\title{
CCR5 and p53 codon 72 gene polymorphisms: Implications in breast cancer development
}

\author{
MATEUS NOBREGA AOKI ${ }^{1}$, ANA CRISTINA DA SILVA DO AMARAL HERRERA ${ }^{1}$, \\ MARLA KARINE AMARANTE ${ }^{1}$, JULIANA LAINO DO VAL CARNEIRO ${ }^{1}$, \\ MARIA HELENA PELEGRINELLI FUNGARO ${ }^{2}$ and MARIA ANGELICA EHARA WATANABE ${ }^{1}$
}

Departments of ${ }^{1}$ Pathological Sciences, ${ }^{2}$ Biology, Biological Sciences Center, State University of Londrina, Londrina, PR, Brazil

Received October 21, 2008; Accepted November 28, 2008

DOI: 10.3892/ijmm_00000148

\begin{abstract}
The aim of this study was to investigate the CCR5 gene and p53 codon 72 polymorphisms in a Brazilian population with breast cancer compared with healthy control subjects and to associate the clinical stage with these genotypes. No differences were detected for the D32 allele between breast cancer patients and the normal healthy donors $(\mathrm{p}=0.270)$, although this allele was more often present in blood donors. For p53 genotype analysis, breast cancer patients presented a significant $(\mathrm{p}<0.05)$ over-representation of p53 Arg homozygosity $(55.5 \%)$ compared with the healthy control group $(33.3 \%)$. Although no statistical difference occurred, a very strong tendency in breast cancer patients in stage III $(\mathrm{p}=0.0503)$ presenting homozygous genotype for Arg was verified. Five breast cancer patients were D32 deletion carriers and two patients presenting metastasis showed homozygous genotype for Arg. It is possible that p53 Arg homozygosity is associated with breast cancer and may represent a potential risk factor for breast tumorigenesis. In the present study, a higher percentage of breast cancer patients presented homozygous genotype for Arg and wild-type for CCR5 than the control subjects.
\end{abstract}

\section{Introduction}

Mammalian cells that sustain oncogenic insults can invoke defensive programs that either arrest cell division or trigger apoptosis, but these countermeasures must be finely tuned to discriminate between physiological and potentially harmful growth promoting states (1).

It is known that p53 effectively limits the proliferation of damaged cells and thus protects against malignancy. Specific

Correspondence to: Professor Maria Angelica Ehara Watanabe, Departamento de Ciências Patológicas, Universidade Estadual de Londrina, Campus Universitário, CEP 86051-970, Londrina, PR, Brazil

E-mail:maewat@uel.br; maewat@pq.cnpq.br

Key words: CCR5, p53, breast cancer stress signals result in posttranslational modifications of p53 and this induces activation of distinct transcriptional programs and outcomes in the cell. p53 activation can effectively inhibit cellular proliferation by inducing cell cycle arrest, apoptosis or senescence. In addition, a variety of negative and positive feedback loops are activated that communicate with signal transduction pathways, modulating the p53 response. Thus, a network of pathways converges upon p53 to tightly regulate its activity (2).

Several studies have reported epidemiological differences in the prevalence or prognostic significance of p53 mutants with arginine or proline at codon 72 polymorphism in certain cancer types, but the biological significance of these variants remains unclear.

Mutations in the p53 gene are considered to represent the most common genetic alterations in human cancers (3). Several studies have focused on $\mathrm{p} 53$ polymorphisms as risk factors for malignant disease. A polymorphic site at codon 72 in exon 4 encodes either an arginine amino acid (Arg) or a proline (Pro) residue (4).

Analysis of data from Siddique et al (5) showed that selective pressure occurs against the expression of the codon 72 p53 Arg allele in the healthy Asian germ line arg/pro heterozygotes and provides insights into the uniqueness of population-based expression of the p53 tumor suppressor gene. It also showed a strong correlation between the expression of the p53 arg allele and susceptibility to breast cancer development.

It is known that chemokines are implicated in tumor pathogenesis, although it is unclear whether they affect human cancer progression positively or negatively. These findings suggest that $\mathrm{CC}$ chemokine receptor 5 (CCR5) activity influences human breast cancer progression in a p53-dependent manner. CCR5 may also have an indirect effect on cancer progression by controlling the antitumor immune response. Results obtained by Mañes et al (6) suggest a negative correlation between CCR5 expression and the growth of human breast tumors expressing wild-type p53.

CCR5 participates in chemotaxis of memory and activated naive $\mathrm{T}$ cells and is required for $\mathrm{T}$ cell activation (7). Physiologically, chemokine receptors mediate the chemotaxis of $\mathrm{T}$ cells and phagocytes to areas of inflammation. The CCR5 gene product is a member of the seven transmembrane 
G-protein-coupled receptor family, which responds to normal B-chemokine ligands, and is involved in the chemotaxis of leukocytes toward inflammation sites. Martinson et al (8) characterized a mutant allele of the $\beta$-chemokine receptor gene CCR5 bearing a 32-bp deletion in the region corresponding to the second extracellular loop of CCR5 (denoted as delta CCR5 or CCR5D32), which prevents cell invasion by the primary transmitting strain of HIV-1. CCR5 is present only in certain cell types, specifically, lymphocytes, dendritic cells and macrophages. The CCR5D32 variant results in a nonfunctional form of the chemokine receptor that is incapable of binding $\beta$-chemokines (Rantes, MIP-1 $\alpha$, MIP-1ß). CCR5D32 causes significant defects in the chemotaxis mediated by these ligands and has been implicated in a variety of immune-mediated diseases (9-11).

In the present study, CCR5 and p53 codon 72 genotype of peripheral blood cells from breast cancer patients and healthy control samples were investigated using a PCR based assay.

\section{Patients and methods}

Study population. The protocol was approved by the Institutional Human Research Ethics Committee of the State University of Londrina, Paraná, Brazil. The individuals were invited to participate, informed in detail regarding the research and voluntary written consent term was obtained from all of the patients enrolled. In this study, $5 \mathrm{ml}$ of peripheral blood was collected with ethylenediaminetetraacetic (EDTA) from 72 breast cancer patients who attended the Cancer Institute of Londrina (Instituto de Câncer de Londrina, ICL) and 90 healthy women subjects provided by the State University of Londrina, Paraná, Brazil. Clinical staging was determined according to the Union of International Control of Cancer (UICC) classification criteria. The tumor node metastasis (TNM) system was initially developed by Pierre Denoix in 1942 and represented an attempt to classify cancer based on the major morphological attributes of malignant tumors that were thought to influence disease prognosis: size of the primary tumor $(\mathrm{T})$, presence and extent of regional lymph node involvement $(\mathrm{N})$ and presence of distant metastases (M).

DNA extraction. Genomic DNA was isolated from peripheral blood cells using the Kirby (12) technique. DNA was extracted from whole blood in the presence of $0.2 \mathrm{M}$ of $\mathrm{NaCl}$ and $0.25 \%$ sodium dodecyl sulfate (SDS), for $4 \mathrm{~h}$ at $37^{\circ} \mathrm{C}$. After precipitation with absolute ethanol, the pellet was dried and resuspended in $50 \mu 1$ of milli-Q water.

DNA amplification of $p 53$ codon 72 by polymerase chain reaction. DNA was amplified by polymerase chain reaction (PCR) with specific primers, described in previously studies $(13,14)$ for p53 codon 72 polymorphism, following the GenBank accession no.: AY838896. Arg sense 5' TCC CCC TTG CCG TCC CAA 3' and Arg antisense 5' CTG GTG CAG GGG CCA CGC 3'; Pro sense 5' GCC AGA GGC TGC TCC CCC 3' and Pro antisense 5' CGT GCA AGT CAC AGA CTT 3' which amplified amplicons of 136 and $178 \mathrm{bp}$, respectively. Reaction conditions for the two PCR were the same: $20 \mathrm{mM}$ Tris-HCl pH 8.4, $50 \mathrm{mM} \mathrm{KCl,} 1.5 \mathrm{mM} \mathrm{MgCl}_{2}$,

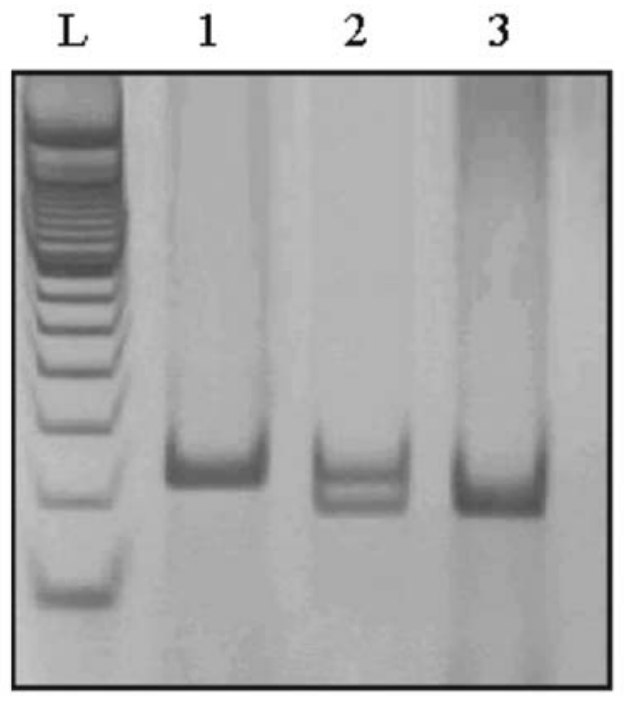

Figure 1. CCR5 genotyping. PCR products were submitted to electrophoresis in $10 \%$ acrylamide gel. Lane 1, wild-type homozygous genotype (CCR5/CCR5) yield 225 bp; Lane 2, heterozygous genotype (D32/CCR5) 225-bp and 193-bp products; Lane 3, homozygous genotype of delta 32-bp (D32/D32) yielded a 193-bp product. L, ladder; B1, Blank reaction or negative control.

$200 \mu \mathrm{M}$ dNTP, 1.25 units of Taq polymerase and $50 \mathrm{ng}$ of genomic DNA. All amplification was performed with appropriate negative controls in parallel to detect contamination. PCR procedure for the arginine amplification was $3 \mathrm{~min}$ for initial denaturation at $94^{\circ} \mathrm{C}, 35$ cycles of $30 \mathrm{sec}$ at $94^{\circ} \mathrm{C}, 30 \mathrm{sec}$ at $60^{\circ} \mathrm{C}$ and $30 \mathrm{sec}$ at $72^{\circ} \mathrm{C}$ and $5 \mathrm{~min}$ elongation at $72^{\circ} \mathrm{C}$, realized in a thermocycler (PCR Sprint, ThermoHybaid, Ashford Middlesex, UK). For proline PCR, the same protocol was used, with exception of the annealing temperature, which was $57^{\circ} \mathrm{C}$.

All the DNA samples were amplified twice, with arginine and proline primers. PCR products were analyzed by electrophoresis on acrylamide gel (10\%) and detected by a nonradioisotopic technique using a commercially available silver staining method.

DNA amplification of CCR5 by PCR. DNA was amplified by PCR using specific primers for CCR5: CCR5.1 (sense, 5'-ACC AGA TCT CAA AAA GAA-3') and CCR5.2 (antisense, 5'-CAT GAT GGT GAA GAT AAG CCT CA-3') (GenBank accession no.: AF009962). Samples were amplified using the kit buffer plus $1.5 \mathrm{mmol} / \mathrm{l}$ Taq polymerase (Invitrogen Life Technologies, Carlsbad, CA, USA). PCR conditions were denaturation at $94^{\circ} \mathrm{C}$ for $5 \mathrm{~min}, 35$ cycles of $1 \mathrm{~min}$ at $94^{\circ} \mathrm{C}, 1 \mathrm{~min}$ at $58^{\circ} \mathrm{C}$ and $1 \mathrm{~min}$ at $72^{\circ} \mathrm{C}$, and $10 \mathrm{~min}$ elongation at $72^{\circ} \mathrm{C}$ in a thermocycler (PCR-Sprint Hybaid, Guelph, Ontario, Canada). All assays included a positive control for 225- and 193-bp ladder controls and a commercially available 100-bp ladder (Invitrogen Life Technologies). PCR products of 225 and $193 \mathrm{bp}$ were analyzed by electrophoresis in 3\% agarose gel and visualized using UV fluorescence after staining with ethidium bromide. A negative control amplification containing no DNA was included in each experimental reaction and no PCR product was detected in this reaction. 
Table I. Demographic characteristics of patients and healthy blood donors.

\begin{tabular}{|c|c|c|c|c|c|}
\hline & \multirow[b]{2}{*}{$\begin{array}{c}\text { Control } \\
(90)\end{array}$} & \multicolumn{4}{|c|}{ Breast cancer (72) } \\
\hline & & $\begin{array}{c}\text { Stage I } \\
(10)\end{array}$ & $\begin{array}{c}\text { Stage II } \\
(30)\end{array}$ & $\begin{array}{l}\text { Stage III } \\
(29)\end{array}$ & $\begin{array}{c}\text { Stage IV } \\
\text { (3) }\end{array}$ \\
\hline \multicolumn{6}{|l|}{ Age (years) } \\
\hline 20-39 & $59(65.55 \%)$ & - & $1(1.38 \%)$ & $4(5.55 \%)$ & - \\
\hline $40-49$ & $19(21.11 \%)$ & $2(2.77 \%)$ & $9(12.5 \%)$ & $7(9.72 \%)$ & $1(1.38 \%)$ \\
\hline $50-59$ & $10(11.11 \%)$ & $4(5.55 \%)$ & $8(11.11 \%)$ & $9(12.5 \%)$ & $1(1.38 \%)$ \\
\hline$>60$ & $2(2.22 \%)$ & $4(5.55 \%)$ & $12(16.66 \%)$ & $9(12.5 \%)$ & $1(1.38 \%)$ \\
\hline \multicolumn{6}{|l|}{ Ethnic group } \\
\hline White & $81(90 \%)$ & $10(13.88 \%)$ & $29(40.27 \%)$ & $25(34.72 \%)$ & $3(4.16 \%)$ \\
\hline Black & $2(2.22 \%)$ & - & $1(1.38 \%)$ & $4(5.55 \%)$ & 0 \\
\hline Brown & $5(5.55 \%)$ & 0 & 0 & 0 & 0 \\
\hline Not informed & $2(2.22 \%)$ & 0 & 0 & 0 & 0 \\
\hline
\end{tabular}

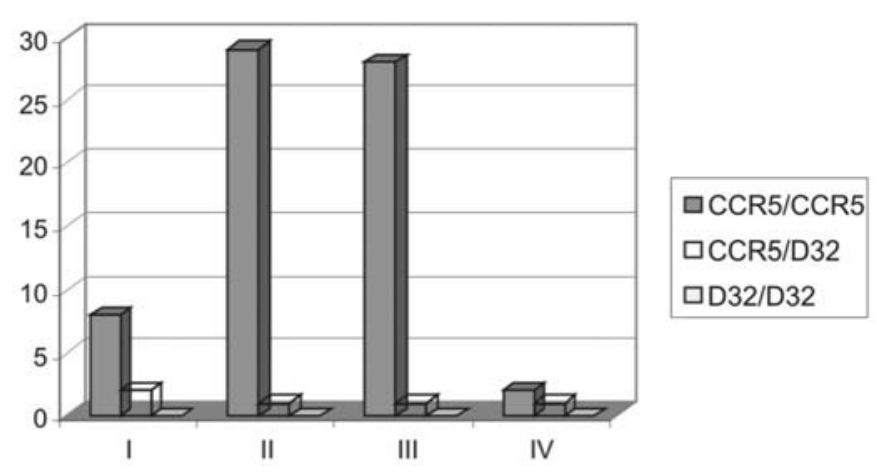

Figure 2. Genotype distribution for CCR5 polymorphism in each clinical stage. The CCR5 genotype was observed throughout the cancer group and in each clinical stage. Statistical significance was not observed between clinical stages and CCR5 genotypes.

Cloning and sequencing. The PCR products were purified using the QIAquick gel extraction kit protocol (Qiagen, Hilden, Germany). After purification, $\mathrm{PCR}^{\circledR} 4-\mathrm{TOPO}^{\circledR}$ vector plasmid (Carlsbad, CA, USA) was used for linked reaction and transformation into Escherichia coli $\mathrm{DH} 5 \alpha$, in accordance with the manufacturer's instructions. Plasmid DNA was obtained using the GFX Micro plasmid prep kit (Amersham Pharmacia Biotech Inc., Piscataway, NJ, USA).

The specificity of the PCR products from CCR5 was analyzed by direct sequencing. DNA was sequenced using the DYEnamic ${ }^{\mathrm{TM}}$ ET dye terminator cycle sequencing kit (Amersham Pharmacia Biotech Inc.) in a MegaBace ${ }^{\mathrm{TM}}$ sequencer (Amersham Pharmacia Biotech Inc.). Sequence analysis of $\mathrm{p} 53$ products was performed and compared with data in the NCBI-NIH database (Blastn), available at http://www.ncbi.nlm.nih.gov/blast.

Statistical analyses. Genotype data were analyzed by the Chi-square $\left(\chi^{2}\right)$ test with the level of significance set at $p<0.05$. Hardy-Weinberg equilibrium was tested using a Chi-square goodness of fit test. Demographic characteristics were evaluated by the t-test, Microcal Origin ${ }^{\mathrm{TM}} 4.1$ (Northampton, MA).

\section{Results}

In the present study, 72 patients aged $20-89$ years old presenting breast cancer, diagnosed at the ICL, Paraná, Brazil, were investigated. Diagnosis of the disease was based on clinical criteria and histopathological analysis, as described in Materials and methods. All patients presented ductal carcinoma and diagnosis of the disease was based on clinical criteria, in accordance with the Union of International Control of Cancer (UICC, 2002). Patient mean age was $56.47 \pm 10.03$ years and $36.08 \pm 13.18$ years for the 90 healthy individuals.

Women aged 40 years or over were formed the greater part of the breast cancer individuals ( $\chi^{2}$ age of breast cancer patients: $13.889,3$ degrees of freedom, $\mathrm{p}=0.0031$ ).

Table I shows age and ethic distribution for all clinical stages. A larger number of patients included in this study presented stages II and III, while the number of patients who presented stages I and IV was relatively small.

To analyze the CCR5 genotype in human breast cancer, the allelic frequency and genotypes of Delta 32 polymorphism was determined in 72 patients presenting breast cancer (Figs. 1 and 2; Table II). None of the patients presented D32/D32, though 5 presented heterozygotes for D32/Wt. The allelic frequency of D32 in the cohort was $3.47 \%$. No differences were detected in allelic frequencies between breast cancer patients and the normal healthy donors $(\mathrm{p}=0.270)$ after Yates' correction. For the CCR5 genotype, the population examined showed no significant deviation from Hardy-Weinberg equilibrium.

A possible association between p53 arginine/proline codon 72 polymorphism and susceptibility to breast cancer was also investigated in this study. To detect the p53 codon 72 polymorphism, two primer sets in separate tubes were used, one to amplify the Arg allele and the other to amplify the Pro allele, which amplified 136 and 178 bp, respectively (Fig. 3).

The mutational status of the p53 gene in peripheral blood samples from breast cancer and blood healthy donors was 
Table II. Genotype distribution in patients and controls.

\begin{tabular}{lcccc}
\hline & \multicolumn{3}{c}{ Genotype $^{c}$} \\
\cline { 2 - 5 } & Number of samples & CCR5/CCR5 & CCR5/D32 & D32/D32 \\
\hline Breast cancer patients $^{\mathrm{a}}$ & 72 & $67(93.05 \%)$ & $5(6.95 \%)$ & - \\
Healthy control subjects $^{\mathrm{b}}$ & 90 & $77(85.56 \%)$ & $12(13.33 \%)$ & $1(1.11 \%)$ \\
\hline
\end{tabular}

${ }^{\mathrm{a}} \chi^{2}$ in HWE $=0.093,2$ degrees of freedom, $\mathrm{p}>0.05 .{ }^{\mathrm{b}} \chi^{2}$ in HWE $=0.448,2$ degrees of freedom, $\mathrm{p}>0.05$. ${ }^{\mathrm{c}}$ Breast cancer patients $\mathrm{x}$ healthy subjects; $\chi^{2}=2.6009, \mathrm{p}=0.270$ ( 2 degrees of freedom, $\mathrm{p}<0.05$ ).

Table III. Genotype distribution in patients and controls.

\begin{tabular}{lcccc}
\hline & \multicolumn{3}{c}{ Genotype } \\
\cline { 2 - 5 } & Number of samples & Arg/Arg & Arg/Pro & Pro/Pro \\
\hline Breast cancer patients $^{\mathrm{a}}$ & 72 & $40(55.5 \%)$ & $29(40.3 \%)$ & $3(4.2 \%)$ \\
Healthy control subjects $^{\mathrm{b}}$ & 90 & $30(33.3 \%)$ & $53(58.9 \%)$ & $7(7.8 \%)$ \\
\hline
\end{tabular}

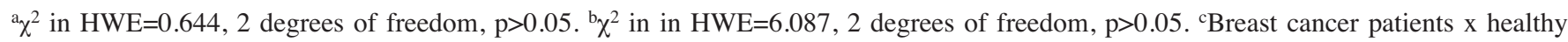
subjects; $\chi^{2}=8.153, \mathrm{p}=0.0170$ ( 2 degrees of freedom, $\left.\mathrm{p}<0.05\right)$.

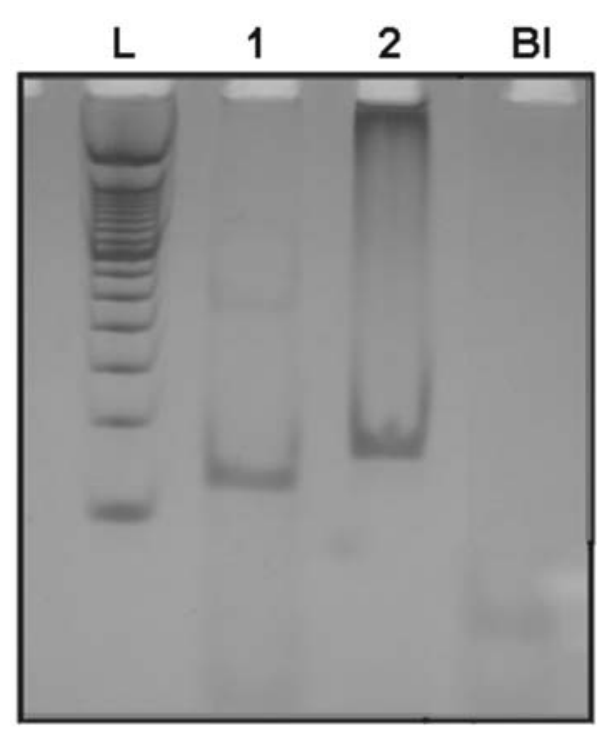

Figure 3. Electrophoretic profile for Arg and Pro genotype for codon 72. PCR amplification of the p53 codon 72 Arg allele (136 bp) and Pro allele (178 bp). The results of Arg homozygote (lane 1) and Pro homozygote (lane 2) genotype amplification are indicated. L, 100-bp ladder; Bl, Blank reaction or negative control.

evaluated. The homozygous genotype Arg/Arg was significantly increased in breast cancer patients compared with blood healthy donors (Table III). In this study, breast cancer blood samples presented a significant genotype for p53 Arg homozygosity $(55.5 \%, 40 / 72)$ compared to control group homozygosity $(33.3 \%, 30 / 90)$. A significant difference between breast cancer patients and controls was obtained for codon 72 polymorphism $(\mathrm{p}<0.05)$. Homozygous genotype for

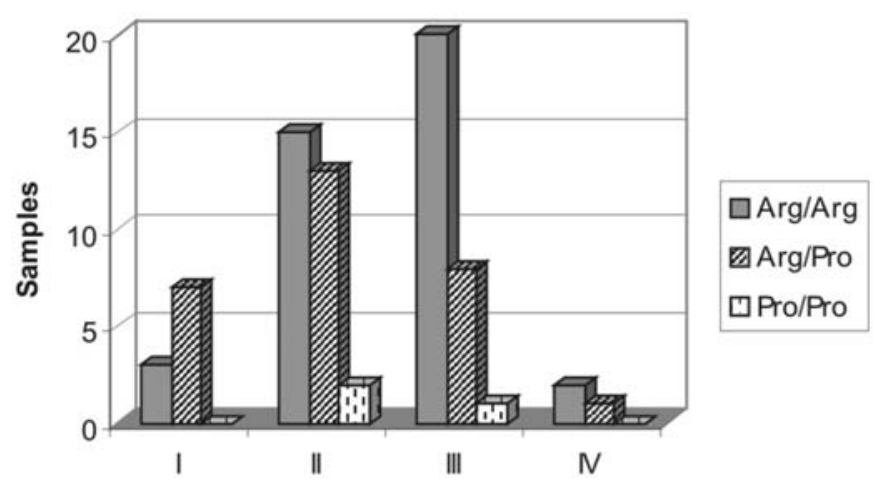

Figure 4. Distribution of genotype for p53 codon 72 polymorphism in each clinical stage. Genotype for p53 codon 72 for the cancer group and each clinical stage. Statistical significance was not observed between clinical stages and p53 codon 72 genotypes. *Breast cancer patients presenting homozygous genotype for Arg in stage III ( $\mathrm{p}=0.0503)$.

Pro was 7.8 and $4.2 \%$ for normal individuals and patients, respectively.

Another clinical aspect investigated in this study was the relation between disease stage and Arg and Pro genotypes. Although no significant difference was observed among the groups, an increase in the homozygous genotype for Arg in clinical stage III was observed $(\mathrm{p}=0.0503)$, a very strong tendency, in comparison with the other stages (Fig. 4).

To analyze primer specificity, three randomly chosen samples were sequenced and compared with data in the NCBI$\mathrm{NIH}$ database. The analysis demonstrated that the amplified fragment was compatible with a sequence in the GenBank register sequences, under accession AF009962 for CCR5 and AY838896 for p53 gene. 
Table IV. Genotype distribution of p53 and CCR5 for healthy control subjects.

\begin{tabular}{ccccc}
\hline & & \multicolumn{3}{c}{$\mathrm{p} 53$} \\
\cline { 3 - 5 } & & Arg/Arg & Arg/Pro & Pro/Pro \\
\hline \multirow{3}{*}{ CCR5 } & CCR5/CCR5 & $27(30.0 \%)$ & $44(48.9 \%)$ & $6(6.7 \%)$ \\
& CCR5/D32 & $3(3.3 \%)$ & $8(8.9 \%)$ & $1(1.1 \%)$ \\
& D32/D32 & - & $1(1.1 \%)$ & - \\
\hline
\end{tabular}

$\chi^{2}=1.185,4$ degrees of freedom, $\mathrm{p}>0.05$.

In Tables IV and V, the genotype distribution for p53 and CCR5 polymorphism in the control subjects and breast cancer patients is shown. In breast cancer patients, homozygous genotype for Arg and wild-type for CCR5 was higher (52.7\%) than in control subjects $(30.0 \%)$.

In this study, only five breast cancer patients presented heterozygous genotype for CCR5, three patients presented heterozygous genotype Arg/Pro without metastasis and two patients presented homozygous genotype for Arg and progression to bone metastasis.

\section{Discussion}

The Brazilian Institute of Geography and Statistics (IBGE) (15) classifies the Brazilian population into five categories: white, black, brown (pardo), yellow and Indigenous, based on skin color. White $(49.9 \%$ of the population) usually describes a Brazilian of full or predominantly European ancestry or other ancestry, such as Arab Brazilian; Brown (pardo; 43.2\%), usually describes a Brazilian of brown skin color and mixed race; Black (6.3\%) usually describes a dark-skinned Brazilian of Black African ancestry; and yellow (0.5\%) usually describes a Brazilian of East Asian descent, mostly Japanese. Although genetic studies reveal a high degree of racial admixture in all ethnic groups in Brazil, the majority population of this study was White (90\%).

Ageing is associated with the inability to maintain and repair somatic cells (16). It has been proposed that ageassociated tissue dysfunction is caused by the accumulation of molecular and cellular damage (17). In this study, the age range in breast cancer patients and healthy women was 25-76 years. Women aged $>40$ years were formed the greater part of the breast cancer population.

It is known that chemokines are important determinants of early inflammatory response. Further studies are required for a clearer understanding of Caucasian gene mixing in the Brazilian population, its relation to immunological molecules and to establish how these polymorphisms could influence on susceptibility or resistance to certain diseases (18). The interpopulational differences in delta 32-bp deletion of CCR5 (D32) and HLA haplotype frequency provide evidence regarding the distribution of numerous immunological molecules that could develop different responses in the host.

Analysis of data obtained in a primary breast cancer clinical series showed that disease-free survival was shorter
Table V. Genotype distribution of p53 and CCR5 for breast cancer patients.

\begin{tabular}{llccc}
\hline & & \multicolumn{3}{c}{$\mathrm{p} 53$} \\
\cline { 3 - 5 } & & Arg/Arg & Arg/Pro & Pro/Pro \\
\hline \multirow{4}{*}{ CCR5 } & CCR5/CCR5 & $38(52.7 \%)$ & $26(36.1 \%)$ & $3(4.2 \%)$ \\
& CCR5/D32 & $2(2.8 \%)$ & $3(4.2 \%)$ & - \\
& D32/D32 & - & - & - \\
\hline
\end{tabular}

$\chi^{2}=0.977,2$ degrees of freedom, $\mathrm{p}>0.05$.

in individuals presenting the CCR5D32 allele than in CCR5 wild-type patients, but only for those whose tumors expressing wild-type p53. These findings suggest that CCR5 activity influences human breast cancer progression in a p53-dependent manner (6).

This study investigated the CCR5 gene in a Brazilian breast cancer population and compared the findings with healthy control subjects. In this study, the examination of 72 breast cancer patients for CCR5D32 deletion showed that $93.05 \%$ (67/72) presented homozygotes for the wild-allele, $6.94 \%$ $(5 / 72)$ carried the D32 allele in the heterozygous state and none presented homozygotes for the variant allele. Despite the small number of samples for D32 allele, analysis of the present results suggests that the D32 allele might not be associated with susceptibility to breast cancer.

It is known that p53 is a classic tumor suppressor that is mutated in the majority of human cancers. p53 functions by arresting cellular proliferation in response to a variety of cellular stresses, including DNA damage, hypoxia and activated oncogenes. It has been postulated that the frequencies of p53 codon-72 genotypes vary according to ethnic group; however, in this study $90 \%$ of the patients were from the Caucasian ethnic group.

Analysis of the data from Siddique et al (5) suggests that the expression of different p53 polymorphisms is selectively regulated in different ethnic populations and that the ARG allele is activated during cancer development in Asians. Thus, the expression status of the $\mathrm{p} 53$ polymorphisms, rather than the genotypic status, might be a useful indicator for cancer susceptibility. It has been verified that breast cancer lesions present a significant over-representation of p53 Arg homozygosity (62\%) compared to p53 Pro homozygosity (21\%) (19).

A subset of molecular alterations have been associated with the development of the disease. p53 is polymorphic at amino acid 72 of the protein that it encodes, thus p53 may contain either a proline or an arginine residue at this position. In the reading frame used, $\mathrm{G}$ or $\mathrm{C}$ at the nucleotide residue 347 resulted in an arginine (CGC) or proline codon (CCC) for the amino acid residue (4).

The current study examined whether p53 Arg at polymorphic position 72 could represent a risk factor for patients with malignant breast lesions in comparison with a normal control group. A significant difference occurred between breast cancer patients and controls for codon 72 polymorphism $(\mathrm{p}<0.05)$. 
Although no significant difference was observed when analyzing the different clinical stages, an increase in the homozygous genotype for Arg was verified for clinical stage III $(\mathrm{p}=0.0503)$ when compared with other stages.

It is possible that the differences between studies reflect the populations under analysis, as inherent differences occur in the relative prevalence of the polymorphic alleles in various populations. Although biochemically different, the significance of p53 codon 72 polymorphism remains controversial in terms of cancer epidemiology. A significant association between codon 72 polymorphism and the risk of cancer had been reported, although the results with regard to most cancer diseases, including breast cancer, remain inconclusive $(19,20)$.

Pezeshki et al (21) demonstrated that the frequency of the Arg allele was significantly higher in sun-exposed patients compared to controls, suggesting that Arg allele at codon 72 of the p53 gene might affect the risk of UV-induced basal cell carcinoma.

Siddique et al (5) verified that Asians were found to preferentially express the Pro allele, whereas Caucasians preferentially express the Arg allele; however, $75 \%$ of heterozygote Chinese breast cancer patients preferentially expressed the Arg allele.

Diminished functional CCR5 can accelerate tumor grown when p53 remains normal, probably due to diminished p21, which acts as a Cdk inhibitor. In studies involving breast cancer patients that provided analyses between tumor classification and CCR5, significant differences were observed between stage IV and CCR5D32, although a low frequency of stage IV patients was observed. Regarding disease-free survival, patients that present CCR5D32 show a significantly lower survival period (6).

It is known that chemokines possess the potential to stimulate $\mathrm{T}$-cell activation, although the pattern of activation may differ for different chemokine-chemokine receptor interactions (22). CCR5 plays an important role in the recruitment of macrophages, monocytes and $\mathrm{T}$ cells at inflammation sites (23), driving an immune response involving a Th1 cytokine pattern (24). CCR5D32 deletion may alter the expression or function of the protein product (25).

van Deventer et al (26) showed that mice expressing CCR5 present enhanced local tumor growth and an impaired response to vaccine therapy compared to CCR5 knockout mice. The authors showed that CCR5 expression in stromal cells, but not hematopoietic cells, contributed to tumor metastasis.

The study verified five breast cancer patients who presented delta 32 deletion and two patients who presented metastasis also presented homozygous genotype for Arg; the number of breast cancer patients presenting homozygous genotype for Arg and wild-type for CCR5 was higher (52.7\%) than among control subjects $(30.0 \%)$.

Understanding cellular and molecular mechanisms of tumor metastasis is critically important for the development of new approaches to cancer treatment. Given the size of the present cohort, strong conclusions are not possible; however, future studies involving much larger cohorts may determine potential clinical implications for Arg and CCR5D32 alleles in relation to breast cancer pathogenesis.

\section{Acknowledgements}

This study was supported by the Conselho Nacional de Desenvolvimento Científico e Tecnológico (CNPq), the Coordenação de Aperfeiçoamento de Pessoal de Nível Superior (CAPES) and the Coordenadoria de Pós-Graduação, Londrina State University, PPG-UEL. Mateus Nóbrega Aoki received a fellowship from CAPES, Brazil.

\section{References}

1. Sherr CJ: Divorcing ARF and p53: an unsettled case. Nat Rev Cancer 6: 663-673, 2006.

2. Harris SL and Levine AJ: The p53 pathway: positive and negative feedback loops. Oncogene 24: 2899-2908, 2005.

3. Vousden $\mathrm{KH}$ and $\mathrm{Lu} \mathrm{X}$ : Live or let die: the cell's response to p53. Nat Rev Cancer 2: 594-604, 2002.

4. Matlashewski GJ, Tuck S, Pim D, Lamb P, Schneider J and Crawford LV: Primary structure polymorphism at amino acid residue 72 of human p53. Mol Cell Biol 7: 961-963, 1987.

5. Siddique MM, Balram C, Fiszer-Maliszewska L, Aggarwal A, Tan A, Tan P, Soo KC and Sabapathy K: Evidence for selective expression of the p53 codon 72 polymorphs: Implications in cancer development. Cancer Epidemiol Biomarkers Prev 14: 2245-2252, 2005.

6. Mañes S, Mira E, Colomer R, Montero S, Real LM, GómezMoutón C, Jiménez-Baranda S, Garzón A, Lacalle RA, Harshman K, Ruíz A and Martinez C: CCR5 expression influences the progression of human breast cancer in a p53dependent manner. J Exp Med 198: 1381-1389, 2003.

7. Taub D, Turcovski S, Key M, Longo D and Murphy W: Chemokines and T lymphocyte activation: I. Beta chemokines costimulate human T lymphocyte activation in vitro. J Immunol 156: 2095-2103, 1996.

8. Martinson JJ, Chapman NH, Rees DC, Liu YT and Clegg JB: Global distribution of the CCR5 gene 32-basepair deletion. Nat Genet 16: 100-103, 1997.

9. Yang X, Ahmad T and Gogus F: Analysis of the CC chemokine receptor (CCR5) Delta32 polymorphism in Behcet's disease, Eur J Immunogenet 31: 11-14, 2004.

10. Oliveira KB, Reiche EMV, Morimoto HK, Fungaro MHP, Estevão D, Pontello R, Nasser TF and Watanabe MAE: Analysis of the CC chemokine receptor 5 delta32 polymorphism in a Brazilian population with cutaneous leishmaniasis. J Cutan Pathol 34: 27-32, 2007.

11. Kaimen-Maciel DR, Reiche EV, Souza DGB, Comini ERF, Bobroff F, Morimoto HK, Watanabe MAE, Oliveira JC, Matsuo T, Lopes J and Donadi EA: CCR $5-\Delta 32$ genetic polymorphism associated with benign clinical course and magnetic resonance imaging findings in Brazilian patients with multiple sclerosis. Int J Mol Med 20: 337-344, 2007.

12. Kirby LT: DNA fingerprinting: an introduction. Stocton Press, New York, NY, 1990.

13. Papadakis ED, Soulitzis N and Spandidos DA: Association of p53 codon 72 polymorphism with advanced lung cancer: the Arg allele is preferentially retained in tumours arising in Arg/Pro germline heterozygotes. Br J Cancer 87: 1013-1018, 2002.

14. Lima JM, Serafim PVP, Silva IDCG and Forones NM: Role of the genetic polymorphism of p53 (codon 72) gene in colorectal cancer. Arq Gastroenterol 43: 8-13, 2006.

15. Instituto Brasileiro de Geografia e Estatística - IBGE: Síntese de Indicadores Sociais, 2006.

16. Kirkwood TB and Austad SN: Why do we age? Nature 408: 233-238, 2000.

17. Hasty P, Campisi J, Hoeijmakers J, van Steeg H and Vijg J: Ageing and genome maintenance: lessons from the mouse? Science 299: 1355-1359, 2003.

18. Muxel SM, Borelli SD, Amarante MK, Voltarelli JC, Aoki MN, Oliveira CEC and Watanabe MAE: Association study of CCR5 delta 32 polymorphism among the HLA-DRB1 Caucasian population in Northern Paraná, Brazil, J Clin Lab Anal 22: 229-233, 2008

19. Papadakis EN, Dokianakis DN and Spandidos DA: p53 codon 72 polymorphism as a risk factor in the development of breast cancer. Mol Cell Biol Res Commun 3: 389-392, 2000. 
20. Weston A and Godbold JH: Polymorphisms of H-ras-1 and p53 in breast cancer and lung cancer: a meta-analysis. Environ Health Perspect 105: 919-926, 1997.

21. Pezeshki A, Sari-Aslani F, Ghaderi A and Doroudchi M: p53 codon 72 polymorphism in basal cell carcinoma of the skin. Pathol Oncol Res 12: 29-33, 2006.

22. Nanki T and Lipsky PE: Stimulation of T-cell activation by CXCL12/SDF-1 involves a G-protein mediated signaling pathway. Cell Immunol 214: 145-154, 2001.

23. Panzer U, Schneider A, Steinmetz OM, et al: The chemokine receptor 5 Delta32 mutation is associated with increased renal survival in patients with IgA nephropathy. Kidney Int 67: 75-81, 2005 .
24. Loetscher P, Uguccioni M, Bordoli L, et al: CCR5 is characteristic of Th1 lymphocytes. Nature 391: 344-345, 1998.

25. Sidoti A, D'Angelo R, Rinaldi C, et al: Distribution of the mutated delta32 allele of the CCR5 gene in a Sicilian population. Int J Immunogenet 32: 193-198, 2005.

26. van Deventer HW, O'Connor W Jr, Brickey WJ, Aris RM, Ting JPY and Serody JS: C-C Chemokine receptor 5 on stromal cells promotes pulmonary metastasis. Cancer Res 65: 3374-3379, 2005. 